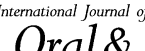 \\ Orala Maxillofacial Surgery \\ Clinical Paper \\ Oral Surgery
}

\section{Comparative efficacy of nimesulide and ketoprofen on inflammatory events in third molar surgery: a split-mouth, prospective, randomized, double-blind study}

E. C. Pouchain, F. W. G. Costa, T. P. Bezerra, E. C. S. Soares: Comparative efficacy of nimesulide and ketoprofen on inflammatory events in third molar surgery: a splitmouth, prospective, randomized, double-blind study. Int. J. Oral Maxillofac. Surg. 2015; 44: 876-884. (C) 2015 International Association of Oral and Maxillofacial Surgeons. Published by Elsevier Ltd. All rights reserved.

Abstract. This study aimed to compare the effect of nimesulide and ketoprofen on inflammatory parameters related to the surgical removal of third molars. A splitmouth, prospective, randomized, double-blind study was conducted in patients undergoing removal of four third molars. Eighteen eligible patients were allocated to one of two groups to receive treatment two times a day with either ketoprofen $100 \mathrm{mg}$ or nimesulide $100 \mathrm{mg}$ for a period of 3 days. The rescue medication intake (number) and pain intensity were evaluated at 6,12, 24, and $48 \mathrm{~h}$, and at 7 days postoperatively. Swelling and maximum mouth opening were evaluated at $24 \mathrm{~h}$, $72 \mathrm{~h}$, and 7 days postoperatively. The peak pain score occurred at $6 \mathrm{~h}$ after surgery in the nimesulide group and at $12 \mathrm{~h}$ in the ketoprofen group. There was no statistically significant difference between the groups, although pain relief was observed after $48 \mathrm{~h}$ in the nimesulide group and after 7 days in the ketoprofen group. For each group, there was a statically significant difference in pain scores among the studied periods $(P<0.0001)$. None of the patients required rescue medication. There was a statistically significant difference in maximum mouth opening between the preoperative and postoperative periods $(P<0.0001)$. Ketoprofen and nimesulide were effective at controlling pain, swelling, and trismus after the surgical removal of third molars.

\author{
E. C. Pouchain ${ }^{a}$, F. W. G. Costa ${ }^{b}$, \\ T. P. Bezerra ${ }^{b}$, E. C. S. Soares ${ }^{\mathrm{b}}$ \\ aPostgraduate Residency Program in Oral \\ and Maxillofacial Surgery, Walter Cantídio \\ University Hospital, Fortaleza, Ceará, Brazil; \\ ${ }^{\mathrm{b}}$ Postgraduate Program in Dentistry, Federal \\ University of Ceará, Fortaleza, Ceará, Brazil
}

Key words: analgesia; third molar; nimesulide; ketoprofen; split-mouth.

Accepted for publication 22 October 2014 Available online 3 April 2015 
The surgical removal of impacted third molars is considered the most common outpatient procedure among oral surgeries. $^{1-3}$ Normally, an inflammatory reaction with pain, swelling, and trismus is observed as a result of this procedure. ${ }^{1-3}$ The removal of third molars is commonly associated with a significant change in quality of life, ${ }^{4}$ particularly during the first three postoperative days. ${ }^{5}$ Therefore, it is necessary to take measures to control the postoperative inflammatory events. Such measures include cryotherapy, ${ }^{6}$ laser application, ${ }^{7}$ and NSAIDs (non-steroidal anti-inflammatory drugs). 8,9

Nimesulide (4-nitro-2-phenoxy methane sulfonanilide) belongs to the group of sulfanilamide derivatives, differing from other NSAIDs by presenting a sulfonanilide radical rather than a carboxylic radical. ${ }^{9}$ This drug is a partially selective cyclooxygenase 2 enzyme (COX-2) inhibitor, used for the treatment of acute pain, such as that associated with osteoarthritis. It is currently accepted for use in countries of different regions of the world, including Europe, Latin America, and Asia. Nimesulide has shown efficacy in the treatment of acute pain associated with different diseases, such as back pain, toothache, postoperative pain and inflammation, and headache and migraine..$^{9-13}$ Its efficiency has been evaluated in more than 200 clinical studies, which have included more than 90,000 patients with inflammatory and acutely painful conditions. ${ }^{9}$ The use of nimesulide in the symptomatic treatment of inflammatory pain is supported by the rapid onset of the analgesic drug effect, which becomes apparent at $15 \mathrm{~min}$ after its administration. Thus, nimesulide is a valuable option when the rapid relief of pain is required. ${ }^{14,15}$

Ketoprofen is an effective inhibitor of cyclooxygenase and prostaglandin synthesis, ${ }^{16}$ demonstrating antipyretic, analgesic, and anti-inflammatory properties. ${ }^{17,18}$ This drug has been used in the treatment of musculoskeletal disorders, and evidence from clinical studies suggests that ketoprofen is as effective as other anti-inflammatories in the reduction of postoperative pain and discomfort. ${ }^{8}$ Following third molar removal, this drug relieves pain approximately $25.5 \mathrm{~min}$ after its administration. ${ }^{19}$

Several clinical trials have been conducted to compare the actions of acetaminophen, ${ }^{1,19,20}$ ibuprofen, ${ }^{19}$ ketorolac, ${ }^{21}$ meloxicam, ${ }^{22}$ ketoprofen, ${ }^{8,20,23,24}$ and nimesulide ${ }^{22,24}$ in the control of inflammatory events after third molar surgery. To date, only one study has been performed to compare the effects of nimesulide and ketoprofen on the inflammation caused by this surgical procedure, and the drugs were administered rectally. ${ }^{25}$ Therefore, we present the results of a split-mouth, prospective, randomized, double-blind trial aimed at assessing and comparing the effects of orally administered nimesulide and ketoprofen on pain, swelling, and trismus in patients undergoing the surgical removal of four third molars under local anaesthesia.

\section{Materials and methods}

\section{Study design and sample}

The present prospective, single-centre, randomized, double-blind pilot study using a split-mouth design was conducted on patients recruited from the division of oral and maxillofacial surgery of the university hospital who required third molar extraction. This study was approved by the university hospital ethics committee and was performed in accordance with the Declaration of Helsinki. Patient recruitment was conducted between April 2011 and June 2012 and followed the guidelines of the CONSORT statement. ${ }^{26}$

This study included healthy subjects (ASA classification I; American Society of Anesthesiologists) of both genders, aged 18-35 years, with an indication for removal of their four third molars and no periodontal disease. The subjects were able and willing to cooperate with the protocol and to sign an appropriate written informed consent form. Furthermore, to standardize the sample, each patient had to have similar patterns of tooth and root formation, position, and impaction degree between the upper and lower third molars of the right and left sides of the mouth. ${ }^{27}$ Patients were excluded if they fulfilled at least one of the following criteria: smoker, pregnant or breast-feeding, using medications that interact with the drugs used in this study, have orthodontic bands on the second molars, a known allergy to NSAIDs, a systemic chronic disease, signs of any pre-existing acute inflammatory or infectious condition, or a history of NSAID use in the past 21 days. Patients who did not follow the indicated recommendations or whose surgery exceeded $2 \mathrm{~h}$ were removed from this study. Patients who did not return for reassessment were also removed.

Patient data were recorded preoperatively and according to a standardized clinical examination, and included gender, age, systemic conditions, periodontal status, haemogram parameters, platelet count, international normalized ratio (INR) value, and blood glucose. Orthopantomograms were required to evaluate tooth variables such as position, Pell and Gregory ${ }^{28}$ and Winter ${ }^{29}$ classifications, tooth/root formation, and degree of impaction.

Patients were scheduled for surgery at two separate clinical sessions (one side at a time) at least 3 weeks apart. Each person had both upper and lower third molars removed at the same time on the involved side. Subjects were allocated to one of two groups according to a computer-generated randomization code to receive treatment two times a day with either ketoprofen $100 \mathrm{mg}$ or nimesulide $100 \mathrm{mg}$ (one tablet every $12 \mathrm{~h}$ for 3 days). The study drugs were dispensed as identical tablets by a blinded collaborator. Prior to the surgical procedure, the method of allocation concealment of the right and left sides of the mouth was followed, as described by Bezerra et al. ${ }^{27}$ Antibiotic prophylaxis was not adopted for the surgical procedure.

\section{Surgical overview}

All patients were submitted to a standardized surgical technique performed in an outpatient setting under local anaesthesia, followed by strict biosafety control. One surgeon with 5 years of experience in dentoalveolar surgery performed all of the surgical procedures. The same surgical procedure was adopted for both sides of the mouth, aiming to reduce the bias related to the intraoperative trauma. Local anaesthesia with $2 \%$ mepivacaine associated with 1:200,000 epinephrine (three cartridges) was administered. A mucoperiosteal flap was raised and bone removal and/or tooth sectioning was performed. The surgical wound was closed using a 4-0 silk suture.

After surgery, $750 \mathrm{mg}$ of acetaminophen was allowed as rescue medication for 7 days if necessary. The postoperative recommendations were carefully read and explained to the patient, in particular the need for a liquid and cold diet for $24 \mathrm{~h}$, rigorous oral hygiene, and to avoid mouthwash. Patients were informed that they should contact the surgeon by telephone in the case of persistent bleeding or any other complications such as fever.

\section{Outcome measures}

The primary outcome of the study was the occurrence of postoperative pain. Measurement of this outcome considered both the pain intensity and the need for rescue analgesia. Postoperative pain intensity was measured using a $10-\mathrm{cm}$ visual analogue scale (VAS) ranging from 0 (absence of pain or discomfort) to 10 (maximum pain 
or discomfort). Before starting the treatment, each patient received an explanation about how to measure pain intensity on this scale. Study participants were asked to record the pain intensity score at 6,12 , 24, 48, and $72 \mathrm{~h}$, and 7 days following surgery. Additional analyses included the evaluation of time to re-medication, which was defined by Ong et al. ${ }^{30}$ as 'the time from the end of surgery until the intake of rescue medication became necessary for the patient'. The number of patients requiring acetaminophen after the surgical procedure and the number of analgesics consumed during the study period were recorded.

The secondary outcome was the occurrence of postoperative inflammatory events. The following measurements were performed to evaluate postoperative swelling on the facial side receiving surgery (Fig. 1): tragus to the soft pogonion (Tr-Pog'), tragus to the external corner of the eye ( $\mathrm{Tr}-\mathrm{Exo})$, tragus to the nasal border $(\mathrm{Tr}-\mathrm{Al})$, tragus to the labial commissure $(\mathrm{Tr}-\mathrm{Che})$, angle of the mandible to the external corner of the eye (Go-Exo), angle of the mandible to the nasal border (Go-Al), angle of the mandible to the soft pogonion (Go-Pog'), and angle of the mandible to the labial commissure (Go$\mathrm{Che}$ ). The differences between the preoperative values (baseline) and those measured at $24 \mathrm{~h}, 72 \mathrm{~h}$, and 7 days after surgery were compared.

To estimate trismus, maximum mouth opening was measured in millimetres between the upper and lower central incisors using a calibrated sliding caliper (TheraBite Range-of-Motion Scales), preoperatively (baseline) and at $24 \mathrm{~h}, 72 \mathrm{~h}$, and 7 days after surgery.

\section{Statistical analysis}

Standard statistical evaluation included the Kolmogorov-Smirnov test to evaluate the normality of the distributions. Pain scores and facial distances did not follow the Gaussian pattern of normality, differing from maximum mouth opening, which did. The Mann-Whitney test was used for comparisons of pain scores and facial distances between the ketoprofen and nimesulide groups. The Friedman test (Dunn post hoc test) was used to assess the same variables (pain score and facial distances) among each of the fixed postoperative time intervals. One-way analysis of variance (ANOVA; Tukey post hoc tests) and the $t$-test were used to assess the means of maximum mouth opening. All data were expressed as the mean \pm standard deviation $(\mathrm{SD})$.

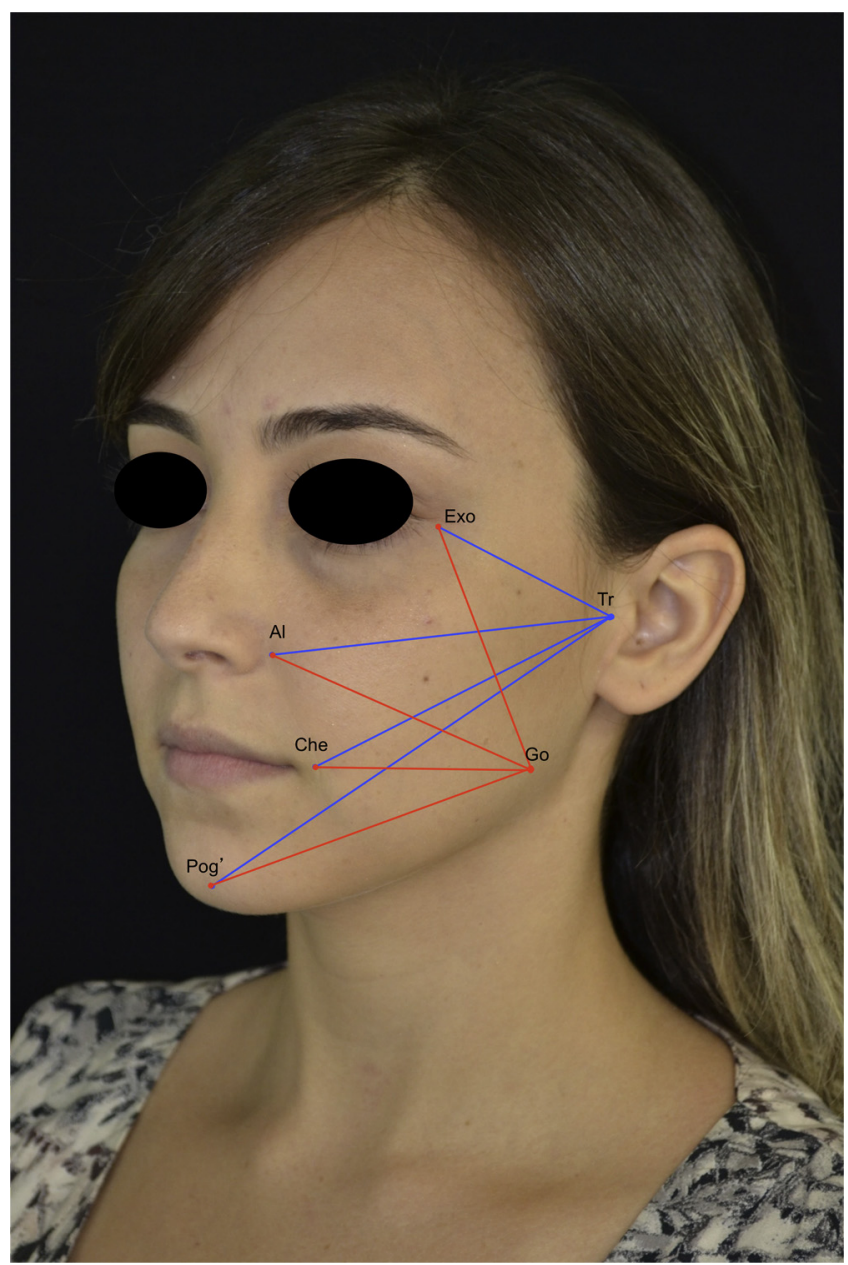

Fig. 1. Facial measurements for the assessment of postoperative swelling. Blue lines: tragus to the external corner of the eye ( $\mathrm{Tr}-\mathrm{Exo})$, tragus to the nasal border $(\mathrm{Tr}-\mathrm{Al})$, tragus to the labial commissure ( $\mathrm{Tr}-\mathrm{Che}$ ), and tragus to the soft pogonion ( $\left.\mathrm{Tr}-\mathrm{Pog}{ }^{\prime}\right)$. Red lines: angle of the mandible to the external corner of the eye (Go-Exo), angle of the mandible to the nasal border (Go-Al), angle of the mandible to the soft pogonion (Go-Pog'), and angle of the mandible to the labial commissure (Go-Che).

Statistical significance was set at there were cases with overlapping exclu$P<0.05$. sion criteria. Thus, an order of priority was adopted for the exclusion criteria.

The study sample comprised 18

\section{Results}

The composition of the final sample in the present study was in accordance with the characteristics of clinical trials using 'split-mouth' as the study design. The experimental units randomly allocated to interventions in split-mouth models are expressed by divisions of the mouth (e.g. dental arches/sides), allowing better control of individual biological responses with a reduced number of recruited individuals. A total of 744 patients were assessed for eligibility in this study (Fig. 2); 724 did not meet the study criteria, one was removed because orthodontic treatment was started with banding of the second molars, and one did not return for follow-up. Among the excluded persons, patients. There were 16 females $(88.9 \%)$ and two males $(11.1 \%)$ and they ranged in age from 18 to 35 years (mean age $19 \pm 4.4$ years). The lower third molars $(n=36)$ were characterized as $1 \mathrm{~A}$ $(n=16), 1 \mathrm{~B} \quad(n=10), 2 \mathrm{~A} \quad(n=4)$, and $2 \mathrm{~B}(n=6)$ according to the Pell and Gregory classification $(P>0.05$; Chi-square test), and as horizontal $(n=2)$, mesioangular $(n=16)$, and vertical $(n=18)$ according to the Winter classification $(P>0.05$; Chi-square test). The upper third molars $(n=36)$ were characterized as $\mathrm{A}(n=22), \mathrm{B}(n=8)$, and $\mathrm{C}(n=6)$ according to the Pell and Gregory classification $(P>0.05$; Chi-square test $)$, and as mesioangular $(n=2)$, vertical $(n=10)$, and distoangular $(n=24)$ according to 


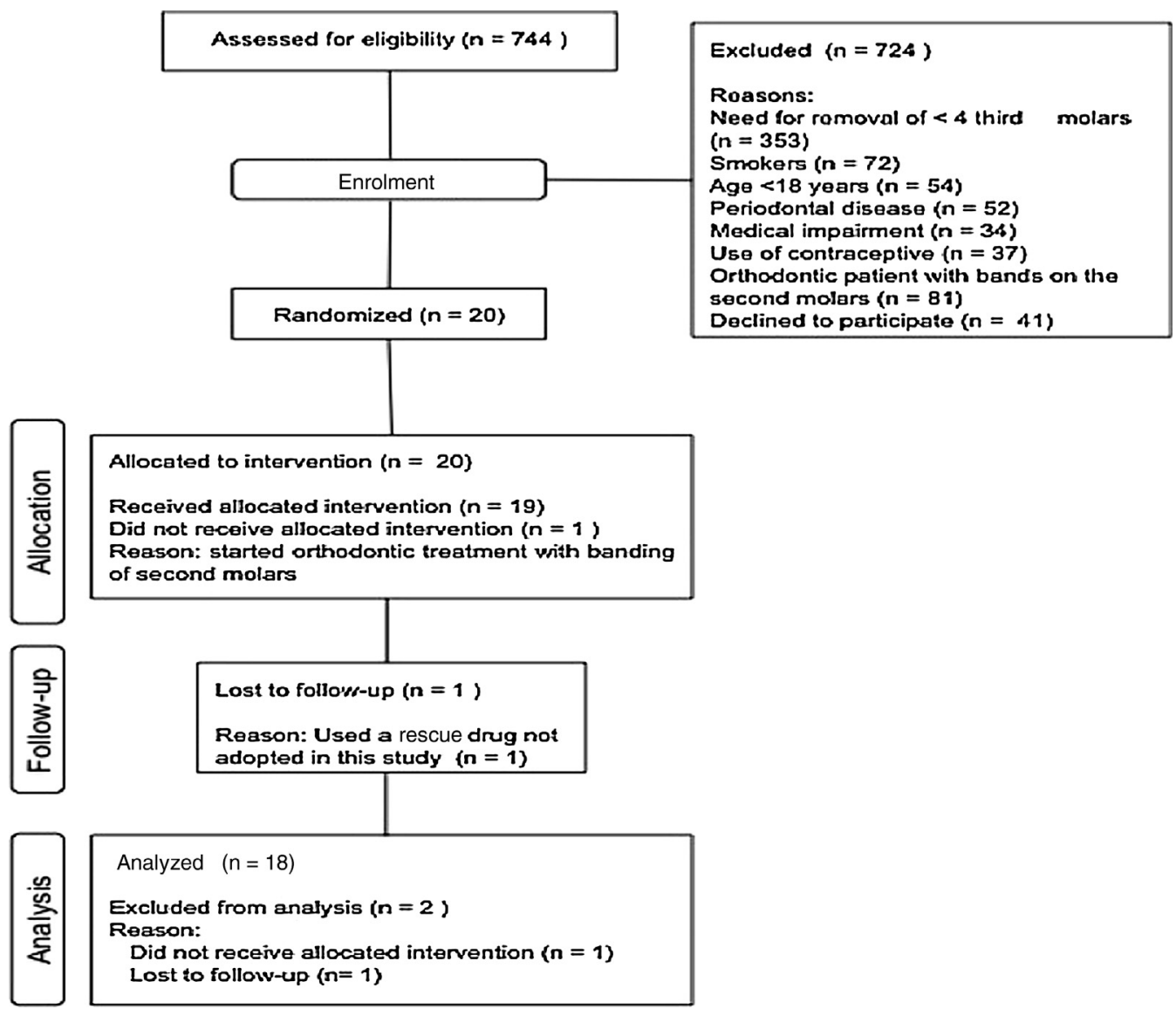

Fig. 2. Flow chart of patient recruitment into this study according to the CONSORT statement.

the Winter classification $(P>0.05$; Chisquare test). The average duration of surgery was $29.9( \pm 7.2)$ min; extractions on the left side took $30.4( \pm 7.3) \mathrm{min}$, while those on the right side took 29.4 $( \pm 7.3) \mathrm{min}$.

\section{Pain intensity}

Comparisons of pain intensity between the groups at each observation time point did not reveal any statistically significant difference (Table 1). Figure 3 illustrates the change in the mean postoperative pain scores across the different observation time points of the study $(6,12,24,48$, and $72 \mathrm{~h}$, and 7 days). The comparison of all observation periods among each group and between the groups showed a statistically significant difference using the Friedman test $(P<0.0001)$. In the ketoprofen group, the Dunn post hoc test identified a difference between the time points of $6 \mathrm{~h}$ and 7 days, and between $12 \mathrm{~h}$ and
7 days (Fig. 4A). In the nimesulide group, a statistically significant difference was found between the time points of $6 \mathrm{~h}$ and $48 \mathrm{~h}, 6 \mathrm{~h}$ and $72 \mathrm{~h}$, and $6 \mathrm{~h}$ and 7 days (Fig. 4B).

\section{Time to rescue analgesia}

After the standardized administration of the study drugs in both groups, only one of the patients required a drug for rescue analgesia during the observation period

Table 1. Pain intensity scores over the study period for the ketoprofen and nimesulide groups.

\begin{tabular}{lllll}
\hline \multirow{2}{*}{ Period after surgery } & \multicolumn{2}{c}{ Pain score $($ mean $\pm \mathrm{SD})$} & \multirow{2}{*}{$P$-value } & \multirow{2}{*}{ Test } \\
\cline { 2 - 4 } & \multicolumn{1}{c}{ Ketoprofen } & Nimesulide & & Mann-Whitney \\
$6 \mathrm{~h}$ & $2.611 \pm 1.914^{\mathrm{a}}$ & $2.611 \pm 1.852^{\mathrm{a}, \mathrm{b}, \mathrm{c}}$ & 0.9872 & Mann-Whitney \\
$12 \mathrm{~h}$ & $2.889 \pm 3.085^{\mathrm{d}}$ & $2.000 \pm 2.612$ & 0.4395 & Mann-Whitney \\
$2 \mathrm{~h}$ & $1.667 \pm 2.249$ & $1.278 \pm 2.191$ & 0.4856 & Mann-Whitney \\
$48 \mathrm{~h}$ & $1.611 \pm 2.547$ & $1.444 \pm 2.791^{\mathrm{b}}$ & 0.5836 & Mann-Whitney \\
$72 \mathrm{~h}$ & $0.9444 \pm 1.798$ & $0.8889 \pm 1.937^{\mathrm{c}}$ & 0.7707 & Mann-Whitney \\
7 days & $0.1111 \pm 0.4714^{\mathrm{a}, \mathrm{d}}$ & $0.2222 \pm 0.6468^{\mathrm{a}}$ & 0.5744 & Mann-Whitney \\
Total & $1.639 \pm 2.318$ & $1.407 \pm 2.209$ & 0.4653 & Friedman/post hoc Dunn \\
$P$-value & $<0.0001$ & $<0.0001$ & &
\end{tabular}

SD, standard deviation.

${ }^{\text {a }}$ Statistically significant difference between $6 \mathrm{~h}$ and 7 days.

${ }^{\mathrm{b}}$ Statistically significant difference between $6 \mathrm{~h}$ and $48 \mathrm{~h}$.

${ }^{\mathrm{c}}$ Statistically significant difference between $6 \mathrm{~h}$ and $72 \mathrm{~h}$.

${ }^{\mathrm{d}}$ Statistically significant difference between $12 \mathrm{~h}$ and 7 days. 


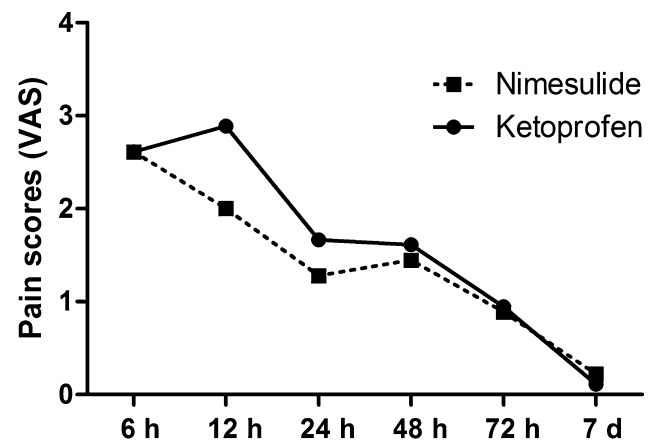

Hours after surgery

Fig. 3. Mean pain intensity scores (VAS) over the study period.

of the study. The patient requiring a rescue drug was removed from the analyzed sample because she took a drug other than acetaminophen $750 \mathrm{mg}$.

\section{Facial swelling and trismus}

At each observation point, there was no statistically significant difference in the mean linear distances between the two studied groups $(P>0.05)$. However, comparing all observation periods between themselves and by group (Table 2), a statistically significant difference was observed for the distances Tr-Al (ketoprofen, $P=0.0029$ ), TrChe (ketoprofen, $P=0.0026$; nimesulide $P<0.0001$ ), Tr-Pog' (ketoprofen,
$P<0.0001 ;$ nimesulide, $P=0.0008)$, Go-Exo (nimesulide, $P=0.0437$ ), Go-Al (nimesulide and ketoprofen, $P<0.0001$ ), Go-Pog' (ketoprofen, $P=0.0087$; nimesulide, $P<0.0001$ ), and Go-Che (ketoprofen, $P=0.0004$; nimesulide, $P<0.0001)$. Table 3 shows the differences between measurements in the preoperative and postoperative periods.

With regard to maximum mouth opening, there was no statistically significant difference $(P>0.05)$ between the preoperative (baseline) and postoperative periods ( 24 h, 72 h, and 7 days) of observation when ketoprofen was compared with nimesulide (Table 4). Individually, ketoprofen and nimesulide showed a statistically significant difference in the maximum mouth opening when the preoperative value was compared to the postoperative periods ( $24 \mathrm{~h}, 72 \mathrm{~h}$, and 7 days) $(P<0.0001 ; \quad$ one-way ANOVA and Tukey post hoc test). For both groups, there was a statistically significant difference at $24 \mathrm{~h}$ and $72 \mathrm{~h}$ after surgery
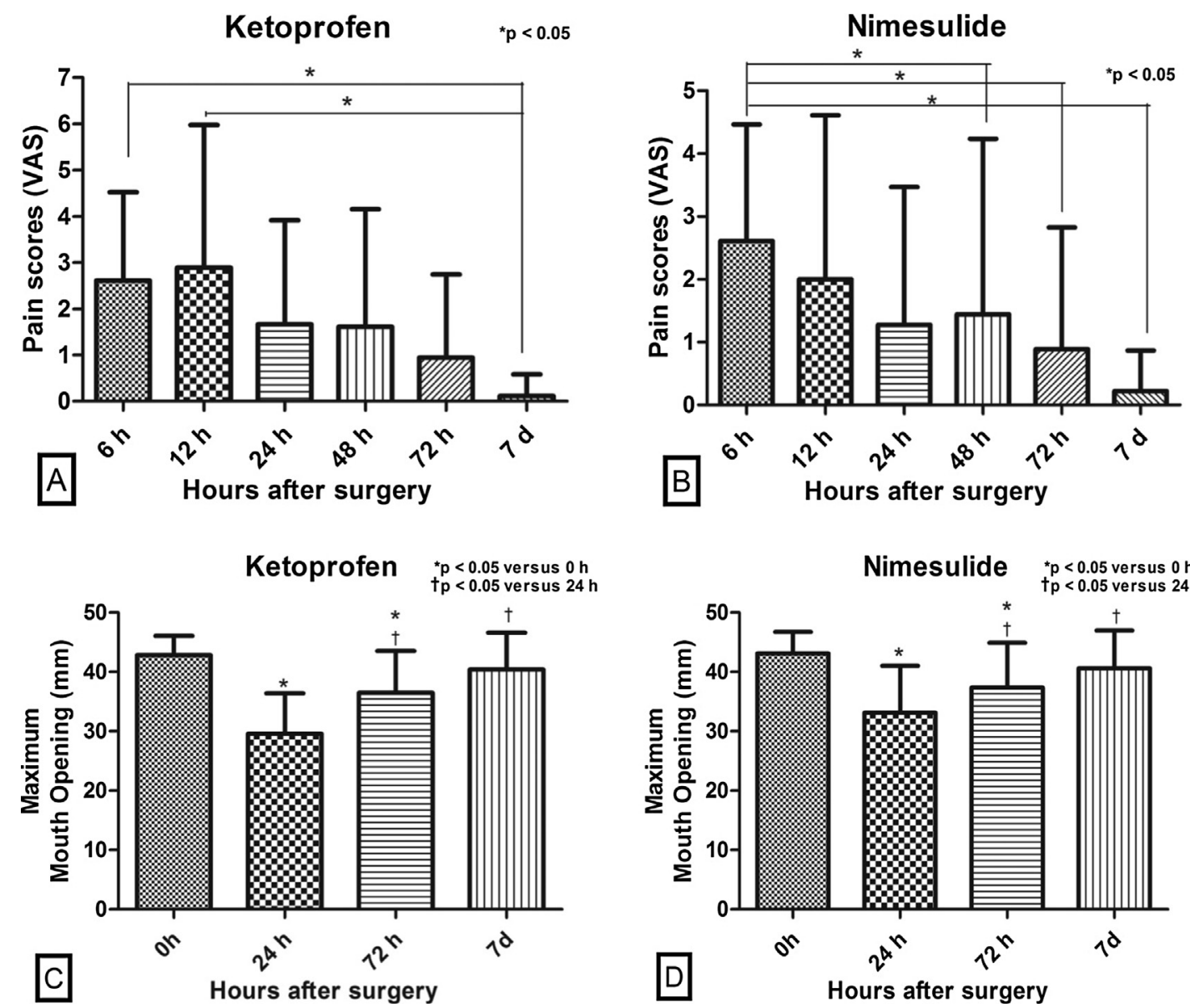

Fig. 4. Pain scores (mean $\pm \mathrm{SD}$ ) in (A) the ketoprofen group, and (B) the nimesulide group; $* P<0.05$, statistically significant difference. Maximum mouth opening (mean \pm SD) before surgery (baseline) and after surgery in (C) the ketoprofen group, and (D) the nimesulide group (the standard was the preoperative value); * statistically significant difference $(P<0.05)$ in relation to the preoperative measurement $($ ANOVA/Tukey post hoc test); ${ }^{\dagger}$ statistically significant difference $(P<0.05)$ in relation to the $24 \mathrm{~h}$ postoperative measurement (ANOVA/Tukey post hoc test). 
Table 2. Assessment of postoperative swelling: $P$-values for differences in measurements tive periods.

\begin{tabular}{lcc}
\hline \multirow{2}{*}{ Distances } & \multicolumn{2}{c}{$P$-value $^{\mathrm{a}}$} \\
\cline { 2 - 3 } & Ketoprofen & Nimesulide \\
\hline Tr-Exo & 0.1873 & 0.9311 \\
Tr-Al & $0.0029^{\mathrm{b}}$ & 0.1621 \\
Tr-Che & $0.0026^{\mathrm{b}}$ & $<0.0001^{\mathrm{b}}$ \\
Tr-Pog & $<0.0001^{\mathrm{b}}$ & $0.0008^{\mathrm{b}}$ \\
Go-Exo & 0.0775 & $0.0437^{\mathrm{b}}$ \\
Go-Al & $<0.0001^{\mathrm{b}}$ & $<0.0001^{\mathrm{b}}$ \\
Go-Pog, & $0.0087^{\mathrm{b}}$ & $<0.0001^{\mathrm{b}}$ \\
Go-Che & $0.0004^{\mathrm{b}}$ & $<0.0001^{\mathrm{b}}$ \\
\hline
\end{tabular}

Tr-Exo, tragus to the external corner of the eye; $\operatorname{Tr}-\mathrm{Al}$, tragus to the nasal border; Tr-Che, tragus to the labial commissure; Tr-Pog', tragus to the soft pogonion; Go-Exo, angle of the mandible to the external corner of the eye; Go-Al, angle of the mandible to the nasal border; Go-Pog', angle of the mandible to the soft pogonion; Go-Che, angle of the mandible to the labial commissure.

${ }^{a}$ Friedman/post hoc Dunn test.

${ }^{\mathrm{b}}$ Statistically significant difference. between the preoperative and all postopera-

$(P<0.05 ; t$-test $)$ in comparison with the baseline value for maximum mouth opening (Fig. 4C, D). In addition, there was a statistically significant difference in maximum mouth opening at $72 \mathrm{~h}$ and at 7 days postoperative $(P<0.05 ; t$-test $)$ when compared with the $24 \mathrm{~h}$ postoperative period (Fig. 4C, D).

\section{Discussion}

The main objective of this research was to conduct a study on two COX-2 partially selective drugs to compare their analgesic efficacy and to analyze their anti-inflammatory effects through a third molar surgery model, with a split-mouth methodology and without a placebo group. The third molar surgery model was chosen because it has been used widely in pharmacological tests since $1976^{31}$ and is a procedure commonly performed in dentistry in which postoperative pain is usually observed in the early stages after the surgical procedure. $^{32}$ This model has been considered important in clinical investigations to

Table 3. Differences in the facial distance measurements taken before surgery in comparison to postoperative values.

\begin{tabular}{llcc}
\hline Distances & \multicolumn{2}{c}{ Difference in cm (mean \pm SD) } & \\
\cline { 2 - 3 } & Ketoprofen & Nimesulide & \\
\hline 24 h & & & \\
Tr-Exo & $0.05 \pm 0.08$ & $0.03 \pm 0.05$ & 0.2576 \\
Tr-Al & $0.17 \pm 0.50$ & $0.18 \pm 0.19$ & 0.9356 \\
Tr-Che & $0.35 \pm 0.25$ & $0.33 \pm 0.29$ & 0.5112 \\
Tr-Pog' & $0.38 \pm 0.34$ & $0.33 \pm 0.32$ & 0.3627 \\
Go-Exo & $0.21 \pm 0.33$ & $0.12 \pm 0.26$ & 0.4090 \\
Go-Al & $0.33 \pm 0.33$ & $0.30 \pm 0.33$ & 0.9235 \\
Go-Pog & $0.14 \pm 0.29$ & $0.28 \pm 0.26$ & 0.1637 \\
Go-Che & $0.38 \pm 0.28$ & $0.33 \pm 0.94$ & 0.5033 \\
72 & & & \\
Tr-Exo & $0.04 \pm 0.15$ & $0.01 \pm 0.10$ & 0.2863 \\
Tr-Al & $0.89 \pm 0.32$ & $0.12 \pm 0.12$ & 0.2313 \\
Tr-Che & $0.25 \pm 0.28$ & $0.25 \pm 0.26$ & 0.7000 \\
Tr-Pog' & $0.33 \pm 0.27$ & $0.28 \pm 0.27$ & 0.4718 \\
Go-Exo & $0.12 \pm 0.35$ & $0.07 \pm 0.25$ & 0.6295 \\
Go-Al & $0.24 \pm 0.30$ & $0.22 \pm 0.28$ & 0.8978 \\
Go-Pog, & $0.06 \pm 0.24$ & $0.12 \pm 0.23$ & 0.7347 \\
Go-Che & $0.27 \pm 0.32$ & $0.24 \pm 0.91$ & 0.7484 \\
days & & \\
Tr-Exo & $0.02 \pm 0.15$ & $0.02 \pm 0.08$ & 0.9151 \\
Tr-Al & $0.33 \pm 0.42$ & $0.08 \pm 0.13$ & 0.1026 \\
Tr-Che & $0.89 \pm 0.26$ & $0.09 \pm 0.16$ & 0.6861 \\
Tr-Pog' & $0.07 \pm 0.23$ & $0.09 \pm 0.20$ & 0.6015 \\
Go-Exo & $0.03 \pm 0.09$ & $0.01 \pm 0.20$ & 0.7558 \\
Go-Al & $0.03 \pm 0.09$ & $0.00 \pm 0.17$ & 0.2135 \\
Go-Pog, & $0.02 \pm 0.07$ & $0.05 \pm 0.82$ & 0.1448 \\
Go-Che & $0.04 \pm 0.17$ & 0.9487 \\
\hline
\end{tabular}

$\mathrm{SD}$, standard deviation; $\mathrm{Tr}-\mathrm{Exo}$, tragus to the external corner of the eye; $\mathrm{Tr}-\mathrm{Al}$, tragus to the nasal border; $\mathrm{Tr}-\mathrm{Che}$, tragus to the labial commissure; $\mathrm{Tr}-\mathrm{Pog}$, tragus to the soft pogonion; Go-Exo, angle of the mandible to the external corner of the eye; Go-Al, angle of the mandible to the nasal border; Go-Pog', angle of the mandible to the soft pogonion; Go-Che, angle of the mandible to the labial commissure.

${ }^{\mathrm{a}}$ Friedman test. distinguish the analgesic effects of different drugs, as performed in this study, and even between different dosages of a single drug. ${ }^{33,34}$ As some patients have bilaterally impacted third molars, they can be the control for themselves. This study design, known as 'split-mouth', 32 enables adequate control of individual variability and requires a smaller number of patients. ${ }^{35}$ Moreover, we agree with Anderson and Cranswick ${ }^{36}$ and Merry et al. ${ }^{37}$ about the unnecessary and unethical use of a placebo in studies using drugs with well-known effects.

In Brazil, both ketoprofen and nimesulide are drugs that are used widely following procedures such as orthopaedic, thoracic, abdominal, and oral surgery, which justifies the interest in studying these two drugs. ${ }^{38-40}$ In a multicentre prospective study involving nine Italian universities, assessing the local protocols of the study services, nimesulide was the most prescribed NSAID, used in $68 \%$ of the cases, whereas ketoprofen was used in only $9 \%$ of the cases. ${ }^{24}$ No study comparing the effects of both of these drugs administered orally using the methodology adopted in the present study has been published to date.

The efficacy of nimesulide and ketoprofen in the control of postoperative pain after dental extraction has been well described in clinical trials. Bjornsson et al., ${ }^{20}$ comparing the use of ketoprofen $75 \mathrm{mg}$ with acetaminophen $1000 \mathrm{mg}$, showed a statistically significant difference between the drugs, with the least amount of pain in the group of patients who received ketoprofen. De Menezes and Cury, ${ }^{22}$ comparing nimesulide $100 \mathrm{mg}$ and meloxicam $75 \mathrm{mg}$, observed lower pain intensity for the nimesulide group. However, the present study did not find any statistically significant difference between the drugs studied in relation to pain scores. This is in agreement with the results of the study by Seymour et al., who evaluated the analgesic efficacy of different doses of ketoprofen (12.5 and $25 \mathrm{mg})$ and acetaminophen (500 and $1000 \mathrm{mg}$ ). Likewise, Leone et al. $^{41} \mathrm{did}$ not find any statistical difference when comparing ketoprofen with methylprednisolone in the control of pain following third molar surgery, even though these drugs are from different groups and have different actions, which highlights the good efficacy of ketoprofen. Furthermore, the greatest pain intensity occurred within the first $12 \mathrm{~h}$ with the use of both drugs in this study, which is in agreement with the results of De Menezes and Cury. ${ }^{22}$ In particular, it was observed that 
Table 4. Comparison of maximum mouth opening (mean $\pm \mathrm{SD}$ ) assessed before and after surgery in the ketoprofen and nimesulide groups. The standard parameter was the preoperative (baseline) measurement of maximum mouth opening $(\mathrm{mm})$.

\begin{tabular}{|c|c|c|c|c|}
\hline \multirow{2}{*}{ Time after surgery } & \multicolumn{2}{|c|}{$\begin{array}{l}\text { Maximum mouth opening } \\
(\text { mean } \pm \text { SD) }\end{array}$} & \multirow{2}{*}{$P$-value } & \multirow{2}{*}{ Test } \\
\hline & Ketoprofen & Nimesulide & & \\
\hline 0 (baseline) & $42.83 \pm 3.2$ & $43.11 \pm 3.6$ & 0.8096 & $t$-Test \\
\hline $24 \mathrm{~h}$ & $29.56 \pm 6.8^{\mathrm{a}}$ & $33.11 \pm 7.9^{\mathrm{a}}$ & 0.1580 & $t$-Test \\
\hline $72 \mathrm{~h}$ & $36.47 \pm 7.0^{\mathrm{a}, \mathrm{b}}$ & $37.36 \pm 7.6^{\mathrm{a}, \mathrm{b}}$ & 0.7168 & $t$-Test \\
\hline 7 days & $40.39 \pm 6.2^{b}$ & $40.61 \pm 6.4^{\mathrm{b}}$ & 0.9162 & $t$-Test \\
\hline$P$-value & $<0.0001$ & $<0.0001$ & & One-way ANOVA \\
\hline
\end{tabular}

$\mathrm{SD}$, standard deviation; ANOVA, analysis of variance.

${ }^{\text {a }}$ Statistically significant difference $(P<0.05)$ in relation to the preoperative measurement (baseline); ANOVA/Tukey post hoc test.

${ }^{\mathrm{b}}$ Statistically significant difference $(P<0.05)$ in relation to the $24 \mathrm{~h}$ postoperative measurement; ANOVA/Tukey post hoc test.

the pain scores were the same for the two drugs at $6 \mathrm{~h}$, but different at $12 \mathrm{~h}$. Bjornsson et al. ${ }^{20}$ observed a similar pain intensity reduction between 4 and $9 \mathrm{~h}$ after surgery in the ketoprofen group, differing from Seymour et al. ${ }^{8}$ who found that the reduction in pain scores occurred at $1 \mathrm{~h}$ after the surgical procedure.

In the present study, both drugs were administered immediately after the surgical procedure and the use of rescue medications for pain was found to be unnecessary. This is in contrast to the studies by Seymour et al. ${ }^{8}$ and Olmedo et al. $^{21}$ The results of the present study suggest that nimesulide and ketoprofen control pain at therapeutic doses and that the routine use of additional postoperative analgesics is unnecessary in third molar surgery. Levrini et al. ${ }^{24}$ observed that $75 \%$ of patients used rescue medication during the early onset of pain ( $3 \mathrm{~h}$ after the surgical procedure) and that $24 \%$ of patients used rescue medication immediately after the surgical procedure.

In the study by Levrini et al., ${ }^{24}$ those patients who used the drug after the onset of pain experienced their peak pain at around $4 \mathrm{~h}$ and $10 \mathrm{~min}$ after surgery; in contrast, the peak maximum pain occurred at $6 \mathrm{~h}$ and $30 \mathrm{~min}$ after surgery in patients who received medication before the onset of pain. Considering the time intervals assessed in the present study to evaluate postoperative pain $(6,12,24$, and $48 \mathrm{~h}$, and 7 days), the peak in pain occurred at $6 \mathrm{~h}$ after the surgical procedure in the nimesulide group and at $12 \mathrm{~h}$ postoperatively in the ketoprofen groups. The pain values decreased significantly after the sixth hour postoperative in the nimesulide group, whereas in the ketoprofen group the pain decreased significantly after the 12th postoperative hour. In addition, nimesulide showed lower pain scores at the $24 \mathrm{~h}, 48 \mathrm{~h}$, and $72 \mathrm{~h}$ intervals than the ketoprofen group, demonstrating a better analgesic efficacy in comparison with ketoprofen. These data show that although complete pain relief was not observed, the pain level was tolerable to patients and they did not require rescue medication.

Regarding oedema, a significant increase was observed in the first $24 \mathrm{~h}$ after the surgical procedure for both drugs evaluated, whereas in the studies of Troullos et al. $^{42}$ and De Menezes and Cury, ${ }^{22}$ the maximum swelling occurred at $48 \mathrm{~h}$ and $72 \mathrm{~h}$, respectively, after the extraction of the third molars. There was no statistically significant difference when the groups in this study were compared with each other, which is in contrast to the results from the study of Bjornsson et al. ${ }^{20}$; they found a statistically significant reduction in swelling on the third and sixth postoperative days for the ketoprofen group. In that study, the reduction in swelling with ketoprofen use was $27.8 \%$ on the third day, increasing to $70.8 \%$ on the sixth day of observation. De Menezes and Cury ${ }^{22}$ observed that the group using nimesulide (100 mg twice a day) had less pronounced swelling compared to the meloxicam group ( $7.5 \mathrm{mg}$ twice a day) during the periods studied. No statistically significant difference in swelling was observed between the nimesulide and ketoprofen groups in relation to the assessed interval periods in the present study.

In both groups studied, $P$-values were less than 0.05 for the differences in measurements between the preoperative period and the postoperative period for six facial measurements. Additionally, five of them (Tr-Pog', Tr-Che, Go-Al, Go-Pog', and Go-Che) showed $P$-values less than 0.0001 . In the study by De Menezes and Cury, ${ }^{22}$ the distance Go-Che was the most affected. These authors observed statistically significant differences for nimesulide in comparison with meloxicam in the
Go-Exo distance at $24 \mathrm{~h}$ postoperative, the Go-Exo and Go-Pog' distances at $48 \mathrm{~h}$ postoperative, and the Go-Exo, Go-Al, Go-Che, and Go-Pog' distances at $72 \mathrm{~h}$ postoperative. These findings are not supported by the present research, since at $72 \mathrm{~h}$ nimesulide did not show any statistically significant difference compared to ketoprofen for all facial swelling measurements.

The assessment of trismus was done by measuring the difference in maximum mouth opening between the postoperative and preoperative periods. A decrease in mouth opening was observed in the first $72 \mathrm{~h}$ after surgery both in this study and in the study performed by De Menezes and Cury. ${ }^{22}$ However, in this study there was no statistically significant difference in the comparison between the nimesulide and ketoprofen groups. A significant increase in mouth opening occurred at $72 \mathrm{~h}$ and at 7 days after surgery in the patients of both groups. This was also found in the study of De Menezes and Cury, ${ }^{22}$ whose patients used nimesulide, as well as in the study of Bjornsson et al., ${ }^{20}$ whose patients used ketoprofen.

Several pharmacological studies have aimed to investigate the tolerability of different drugs. Olmedo et al. ${ }^{21}$ recruited patients to analyze the drug safety of ketorolac and ketoprofen. Adverse effects were transient in all patients who presented one, and none of the patients required adjuvant treatment. In the study by Olmedo et al., ${ }^{21} 37.3 \%$ of the patients reported some type of adverse effect, with drowsiness being the most prevalent ( $10.7 \%$ of cases), followed by gastric disturbances $(8 \%)$ and dizziness $(5.3 \%)$. The most prevalent adverse effect related to ketoprofen was pyrosis $(10.3 \%)$. Three serious adverse effects were reported by Olson et al., ${ }^{19}$ with two of these events related to ibuprofen and one related to acetaminophen. No adverse effect, such as gastrointestinal discomfort, dizziness, or nausea, was related to the use of ketoprofen in this study. Bjornsson et al. ${ }^{20}$ stated that the adverse effects that deserve special attention are those associated with the gastrointestinal tract (stomach ache and diarrhoea). In that study, all adverse effects were reported to be of mild to moderate intensity. ${ }^{20}$ Ketoprofen and other strong NSAIDs have been associated with a risk of gastric irritation. ${ }^{43-45}$ Unlike those studies, none of the patients evaluated in the present clinical trial experienced adverse effects related to the use of drugs during the study period. This fact is probably due to the short period (3 days) that was adopted in the methodology. It is 
reasonable to assume that a relatively short duration of the ketoprofen drug regimen represents a limited risk to the patient who has had no previous experience of gastrointestinal problems or reactions to other NSAIDs. $^{20}$

De Menezes and Cury $^{22}$ described no adverse effects in patients who used nimesulide. In a review of hepatic adverse effects, a greater number and severity of hepatotoxic events was demonstrated for patients who used nimesulide in relation to other NSAIDs. ${ }^{45}$ Mació et al. ${ }^{45}$ found that the patients with a higher risk of hepatotoxicity with nimesulide use were older, female, and had a median of 62 days using this drug. Different from that work, the patients in the research by De Menezes and Cury $^{22}$ and in the present study were younger (average age around 20 years) and used nimesulide for a very short period of time.

The present research was a comparative study of ketoprofen and nimesulide administered orally following surgery for the removal of third molars. In summary, patients who received ketoprofen $100 \mathrm{mg}$ or nimesulide $100 \mathrm{mg}$ showed good control of pain, swelling, and trismus after the extraction of the third molars.

\section{Funding}

None.

\section{Competing interests}

None declared.

\section{Ethical approval}

This study was approved by the Ethics Committee of the Walter Cantídio University Hospital, Ceará, Brazil (protocol number 084.08.11) and was conducted in accordance with the Helsinki statements.

\section{Patient consent}

The patient provided informed consent for the use of the data and the photograph in this publication.

\section{References}

1. Seymour RA, Meechan JG, Blair GS. An investigation into post-operative pain after third molar surgery under local analgesia. $\mathrm{Br}$ J Oral Maxillofac Surg 1985;23:410-8.

2. Clauser C, Barone R. Effect of incision and flap reflection on postoperative pain after the removal of partially impacted mandibular third molars. Quintessence Int 1994;25: 845-9.
3. Berge TI, Egil O. Predictor evaluation of postoperative morbidity after surgical removal of mandibular third molar. Acta Odontol Scand 1994;52:162-9.

4. McGrath C, Comfort MB, Lo EC, Luo Y. Changes in life quality following third molar surgery - the immediate postoperative period. Br Dent J 2003;194:265-8.

5. Colorado-Bonnin M, Valmaseda-Castellón E, Berini-Aytés L, Gay-Escoda C. Quality of life following lower third molar removal. Int J Oral Maxillofac Surg 2006;35: 343-7.

6. Sortino F, Messina G, Pulvirenti G. Evaluation of postoperative mucosa and skin temperature after surgery of impacted third molar. Minerva Stomatol 2003;57:393-9.

7. Markovic AB, Todorovic L. Postoperative analgesia after lower third molar surgery: contribution of the use of long-acting local anesthetics, low-power laser and diclofenac. Oral Surg Oral Med Oral Pathol Oral Radiol Endod 2006;12:e4-8.

8. Seymour RA, Kelly PJ, Hawkesford JE. The efficacy of ketoprofen and paracetamol (acetaminophen) in postoperative pain after third molar surgery. $\mathrm{Br} \mathrm{J} \mathrm{Clin} \mathrm{Pharmacol}$ 1996;41:581-5.

9. Rainsford KD. Nimesulide: a multifactorial approach to inflammation and pain: scientific and clinical consensus. Curr Med Res Opin 2006;2:1161-70.

10. Binning A. Nimesulide in the treatment of postoperative pain: a double-blind, comparative study in patients undergoing arthroscopic knee surgery. Clin J Pain 2007;23: 565-70.

11. Ferrari A, Pasciullo G, Savino Cicero AF, Ottani A, Bertolini A, Sternieri E. Headache treatment before and after the consultation of a specialized center: a pharmacoepidemiology study. Cephalalgia 2004;24:356-62.

12. Pohjolainen T, Jekunen A, Autio L, Vuorela $\mathrm{H}$. Treatment of acute low back pain with the COX-selective anti-inflammatory drug nimesulide: results of a randomized, double-blind comparative trial versus ibuprofen. Spine (Phila Pa 1976) 2000;25:1579-85.

13. Wober W. Comparative efficacy and safety of nimesulide and diclofenac in patients with acute shoulder, and a meta-analysis of controlled studies with nimesulide. Rheumatology (Oxford) 1999;38:33-8.

14. Bianchi M, Broggini M. A randomised, double-blind, clinical trial comparing the efficacy of nimesulide, celecoxib and rofecoxib in osteoarthritis of the knee. Drugs 2003;63: 37-46.

15. Bianchi M, Broggini M. Anti-hyperalgesic effects of nimesulide: studies in rats and humans. Int J Clin Pract 2002;128:11-9.

16. Jamali F, Brocks DR. Clinical pharmacokinetics of ketoprofen and its enantiomers. Clin Pharmacokinet 1990;19:197-217.

17. Fossgreen J. Ketoprofen - a survey of current publications. Scand J Rheumatol 1976;14: 7-32.
18. Kantor TG. Ketoprofen: a review of its pharmacologic and clinical properties. Pharmacotherapy 1976;6:93-103.

19. Olson NZ, Otero AM, Marrero I, Tirado S, Cooper S, Doyle G, et al. Onset of analgesia for liquigel ibuprofen $400 \mathrm{mg}$, acetaminophen $1000 \mathrm{mg}$, ketoprofen $25 \mathrm{mg}$, and placebo in the treatment of postoperative dental pain. J Clin Pharmacol 2001;41:1238-47.

20. Bjornsson GA, Haanaes HR, Skoglund LA. Ketoprofen $75 \mathrm{mg}$ qid versus acetaminophen $1000 \mathrm{mg}$ qid for 3 days on swelling, pain and other postoperative events after third molar surgery. J Clin Pharmacol 2003;43:305-14.

21. Olmedo MV, Gálvez R, Vallecillo M. Double-blind parallel comparison of multiple doses of ketorolac, ketoprofen and placebo administered orally to patients with postoperative dental pain. Pain 2001;90:135-41.

22. De Menezes SA, Cury PR. Efficacy of nimesulide versus meloxicam in the control of pain, swelling and trismus following extraction of impacted lower third molar. Int J Oral Maxillofac Surg 2010;39:580-4.

23. Seymour RA, Watkinson H, Hawkesford JE, Moore U. The efficacy of buffered ketoprofen in postoperative pain after third molar surgery. Eur J Clin Pharmacol 2006;55: 801-6.

24. Levrini L, Carraro M, Rizzo S, Salgarello S, Bertelli E, Pelliccioni GA, et al. Prescriptions of NSAIDs to patients undergoing third molar surgery: an observational, prospective, multicentre survey. Clin Drug Invest 2008; 28:657-68.

25. Pierleoni P, Tonelli P, Scaricabarozzi I. A double-blind comparison of nimesulide and ketoprofen in dental surgery. Drugs 1993;46:168-70.

26. Moher D, Hopewell S, Schulz KF, Montori V, Gøtzsche PC, Devereaux PJ, et al. CONSORT 2010 explanation and elaboration: updated guidelines for reporting parallel group randomised trials. J Clin Epidemiol 2010;63:e1-37.

27. Bezerra TP, Studart-Soares EC, Scaparo HC, Pita-Neto IC, Batista SH, Fonteles CS. Prophylaxis versus placebo treatment for infective and inflammatory complications of surgical third molar removal: a split-mouth, double-blind, controlled, clinical trial with amoxicillin (500 mg). J Oral Maxillofac Surg 2011;69:e333-9.

28. Pell GJ, Gregory BT. Impacted mandibular third molars: classification and modified techniques for removal. Dent Dig 1933;39: 330-8.

29. Winter GB. Principles of exodontia applied to the impacted mandibular third molar. Saint Louis: American Books; 1926.

30. Ong KS, Seymour RA, Chen FG, Ho VC. Preoperative ketorolac has a preemptive effect for postoperative third molar surgical pain. Int J Oral Maxillofac Surg 2004;33:771-6.

31. Cooper SA, Beaver WT. A model to evaluate mild analgesics in oral surgery outpatients. Clin Pharmacol Ther 1976;20:241-50. 
32. Meechan JG, Seymour RA. The use of third molar surgery in clinical pharmacology. $\mathrm{Br} J$ Oral Maxillofac Surg 1993;31:360-5.

33. Forbes JA. Oral surgery. In: Max ME, Portenoy RK, Laska EM, editors. Advances in pain research and therapy. The design of analgesic clinical trials. New York: Raven Press; 1991. p. 347.

34. Van Aken H, Thys L, Veekman L, Buerkle H. Assessing analgesia in single and repeated administrations of propacetamol for postoperative pain: comparison with morphine after dental surgery. Anesth Analg 2004;98: 159-65.

35. Lesaffre E, Garcia Zattera MJ, Redmond C, Huber H, Needleman I, ISCB Subcommittee on Dentistry. Reported methodological quality of split-mouth studies. J Clin Periodontol 2007;34:756-61.

36. Anderson B, Cranswick N. The placebo (I shall please) - is it so pleasing in children? Pediatr Anaesth 2005;15:809-13.

37. Merry AF, Gibbs RD, Edwards J, Ting GS, Frampton C, Davies E, et al. Combined acetaminophen and ibuprofen for pain relief after oral surgery in adults: a randomized controlled trial. Br J Anaesth 2010;104: 80-8.
38. Arrais PS, Coelho HL, Batista MC, Carvalho ML, Righi RE, Arnau JM. Profile of selfmedication in Brazil. Rev Saude Publica 1997;31:71-7. [in Portuguese].

39. Pereira FS, Bucarethi F, Stephan C, Cordeiro R. Self-medication in children and adolescents. J Pediatr (Rio J) 2007;83:453-8.

40. Castilho LS, Paixão HH, Perini E. Prescription patterns of drugs of systemic use by dentists. Rev Saude Publica 1999;33: 287-94.

41. Leone M, Richard O, Antonini F, Rousseau S, Chabaane W, Guyot L, et al. Comparison of methylprednisolone and ketoprofen after multiple third molar extraction: a randomized controlled study. Oral Surg Oral Med Oral Pathol Oral Radiol Endod 2007; 103:e7-9.

42. Troullos ES, Hargreaves KM, Butler DP, Dionne RA. Comparison of nonsteroidal anti-inflammatory drugs, ibuprofen and flurbiprofen, with methylprednisolone and placebo for acute pain, swelling, and trismus. $J$ Oral Maxillofac Surg 1990;48:945-52.

43. Henry D, Lim LL, Rodrigues LA, Perez Gutthann S, Carson JL, Griffin M, et al. Variability in risk of gastrointestinal complications with individual non-steroidal anti-inflammatory drugs: results of a collaborative meta-analysis. $\mathrm{Br}$ Med J 1996;312: 1563-6.

44. Lanza FL, Codispotti JR, Nelson EB. An endoscopic comparison of gastroduodenal injury with over-the-counter doses of ketoprofen and acetaminophen. Am J Gastroenterol 1998;93:1051-4.

45. Mació MA, Carvajal A, Vera E. Hepatotoxicity associated with nimesulide: data from the Spanish pharmacovigilance system. Clin Pharmacol Ther 2001;72:696-7.

\section{Address:}

Fábio Wildson Gurgel Costa

Postgraduate Program in Dentistry

Federal University of Ceará

Rua Monsenhor Furtado

Rodolfo Teófilo

Fortaleza

Ceará $60430-350$

Brazil. Tel.: +55 8599981426 ;

Fax: +558533668232

E-mail: fwildson@yahoo.com.br 